\title{
Nitric oxide and physical exercise: modulations in physiological systems during elderly
}

\author{
Samuel da Silva Aguiar ${ }^{1,4}$, Shirko Ahmadi ${ }^{2}$, Rodrigo Silveira ${ }^{3}$, Raul Cosme Ramos do Prado ${ }^{3}$,
} Henrique de Oliveira Castro ${ }^{4}$, Ricardo Yukio Asano ${ }^{3}$, Hélio José Coelho-Júnior ${ }^{2}$

\begin{abstract}
Background: Nitric oxide (NO) is a gaseous substance, which act as a key factor on the regulation of some physiological systems activity (e.g. cardiovascular, skeletal), since decrease on NO biodisponibility, such as on the pathway responsible for its production, lead to impairment on body homeostasis. Besides chronic pathological conditions, senescence - which is conceited as the healthy aging - NO levels and its pathway also can be found decreased. In front of this scenario, it is possible observe that there is necessity of therapies that act collaborating with the maintaining of a favorable environment to NO synthesis, as well to development of its functions during aging. Some trial has been observed in animals and in human beings the capacity of physical exercise to act collaborating to NO activity maintaining during senescence and senility. Objectives: To evaluate the effect of physical training on activity of pathway responsible for NO formation, as well as its blood concentrations in animal and elderly human models. Methods: A literature search was performed in the PubMed, Web of Science, Scielo and Lilacs databases, that evaluated the effects of physical training and nitric oxide formation in animal and elderly human models. Results: According to the studies reviewed in this research, pathway of the NO synthesis improves through physical exercise in animal and elderly human models. Conclusion: Scientific evidences demonstrate effectiveness of the physical exercise in inhibiting decrease of bioavailability in NO which accompanies senescence, greater magnitude and senility.

Keywords: Physical Exercise; Nitric Oxide; Elderly.
\end{abstract}

\section{INTRODUCTION}

The vascular endothelium is able to secrete bioactive substances which act as a regulating activity of several physiological systems. During this time, the vascular endothelium may have a deleterious effect on its function (i.e., endothelial dysfunction), a process related to genesis of some chronic degenerative conditions (e.g., systemic arterial hypertension) (In order to evaluate the effects of enzymatic activity on enzymatic activity of microorganisms $\mathrm{s}^{(1-3)}$. The oxidative stress, a phenomenon characterized by the imbalance between oxidant molecules and antioxidants, is suggested as a main modulator of the loss of vascular endothelium's ability to synthesize the vasoactive substances ${ }^{(3)}$. In general, the reactive oxygen species are synthesized in organic system and act on body homeostasis, collaborating in processes ranging from regulation of vascular tone to digestion of pathogens. However, phenomena that are indicated as an inherent to aging (e.g. hypotonic, increased body fat) can cause exacerbation of pro-oxidant molecules to point that they would not be able to control antioxidant system, leading to oxidative stress $^{(3)}$. In the present study, asymmetry in the vascular endothelium is the most important factor in the regulation of vascular tone in vascular endothelium ${ }^{(4)}$. However, it is known that the signaling and Nitric oxide (NO) activity in muscular, nervous and bone systems are essential for proper functioning of NO, acting on the homeostasis of any human organic system $^{(1,2,4)}$. In fact, decreasing in NO can increase activity of pathways responsible for inflammatory process, as well as may be associated with genesis of some chronic degenerative states (e.g. systemic arterial hypertension, Alzheimer's disease) $)^{(3)}$. In the state of oxidative stress, oxidant molecules (also known as reactive oxygen species [ROS]) react with cofactors responsible for the formation of NO, indirectly causing their synthesis to be degraded, by degrading cofactors which act in their production, as well as reacting directly with NO causing its inhibition ${ }^{(3)}$. Both processes (direct and indirect) cause an increase in production of ROS, in conclusion, this phenomenon feeds itself. In above view, it is possible to observe decreases in NO concentrations present in elderly population, and may contribute to increase in prevalence of chronic degenerative diseases. Therefore, finding therapies

Corresponding author: Hélio José Coelho-Júnior. Address: Universidade Estadual de Campinas, Faculdade de Educação Física, Departamento de Estudos da Atividade Adaptada. Avenida Érico Veríssimo, 701. Barão Geraldo. CEP 13083-851 - Campinas (SP), Brasil. Phone: 0055 19 35216750. E-mail: coelhojunior@hotmail.com.br

2 Laboratório de Cinesiologia Aplicada -LCA - Universidade Estadual de Campinas, Campinas (SP), Brazil.

Full list of author information is available at the end of the article.

Financial Support: nothing to declare.

Submission date 19 July 2018; Acceptance date 13 September 2018; Publication date 28 December 2018 
that can contribute to maintenance of NO concentrations is essential for health of elderly.

Physical exercise is indicated as a possible positive modulator of NO concentrations ${ }^{(4)}$. In acute experiments, physical exercise has been able to increase NO concentrations in humans with different morbidities ${ }^{(4)}$. Chronically, some studies have also evaluated ability of physical exercise to increase NO concentrations, most of them were in animal model(5-8). Thus, the present study aimed to evaluate the effect of physical training on activity of pathway responsible for NO formation, as well as its blood concentrations in animal and elderly human models.

\section{METHODOLOGY}

A literature search was performed in the PubMed, Web of Science, Scielo and Lilacs databases, that evaluated the effects of physical training and nitric oxide formation in animal and elderly human models.

\section{DISCUSSION}

\section{NO and exercise in elderly animal model}

In above, it is possible to conclude that the decrease in bioavailability of NO with old age, especially when marked by senility, may cause a decrease in endothelial function, contribute to establishment of oxidative stress, lead to chronic inflammation, thus favoring appearance of pathologies. Thus, therapies that collaborate to maintain endothelial function and its ability to produce NO are extremely important in this age group. Muscle contraction can cause increased mechanical stress in blood vessel (i.e., shear stress), which elicits eNOS activation and NO synthesis ${ }^{(9)}$. In this way, physical exercise appears as a possible therapy capable of collaborating to maintain bioavailability of NO in organic system, avoiding or delaying appearance of chronic degenerative diseases. Unfortunately, economic, cultural, and motivational factors prevent seniors from participating in regular and planned physical exercise programs ${ }^{(4)}$. Thus, some recommendations suggest that physical activity achievements can be used as measures that contribute to the improvement and maintenance of quality of life and health in elderly population. The term physical activity refers to any body movement produced from voluntary contraction of skeletal muscle, which raises caloric expenditure above resting values ${ }^{(10)}$. Some publications suggest that small changes in daily activities, such as replacing elevator use with stairs, parking car away from market entrance, and getting off a bus stop before destination, for example, can collaborate with best salutary in elderly life. Bearden et al. ${ }^{(11)}$ investigated effect of voluntary running on vasodilatory capacity of arteries of elderly mice. For eight weeks' mice remained in individual boxes, which had a device that quantified distance walked voluntarily by animals. The results showed no significant changes in
eNOS mRNA, but there was a significant increase in protein expression. Despite this, eight weeks of physical activity were not able to prevent deterioration of endothelium-dependent vasodilator capacity of arteries of elderly mice, since there were no differences in vasodilator capacity between sedentary and active elderly mice. However, effect of physical activity on endothelium-dependent vasodilation may be timedependent ${ }^{(12)}$. In the study by Durant et al. ${ }^{(12)}$ mice's that had endothelial dysfunction with age were followed for 12 weeks. The researchers observed that control group had systemic and carotid impairment in ACh-mediated endothelial vasodilation. In contrast, elderly mice's that exercised voluntarily for 12 weeks had a systemic and carotid increase of ACh-mediated vasodilation compared to control group. The researchers observed, after infusion of L-NAME, endothelium-dependent vasodilation found in elderly mice that had been exercised had a $28 \%$ reduction. In addition, active mice showed increased expression of eNOS protein and its activity (phosphorylated eNOS), which was lower in sedentary mice.

Physical exercise is a programmed, structured and organized activity that aims to increase one or more physical capacities $^{(10)}$. This type of intervention may be more beneficial than FA because of its programmed, evidence-based basis and grounded in accordance with principles of physical training. In experiments performed by Spier and colleagues, the authors evaluated impact of 12 weeks of aerobic exercise on endothelium-dependent vasodilation in arterioles of soleus and gastrocnemius muscle of elderly rats ${ }^{(13,14)}$. The researchers observed that after physical training group of elderly rats showed endothelium-dependent vasodilatation equal to that observed in group of young sedentary rats and higher than in the elderly sedentary rats. However, when NO production was inhibited by L-NAME infusion, vasodilatory capacity of trained elderly rats was abolished, and matched to sedentary elderly rats. In addition, physical exercise caused increased mRNA expression and eNOS protein activity.

Similar to aforementioned study, Trott et al. ${ }^{(15)}$ found that 12 weeks of aerobic exercise was able to reverse impairment of ACh-induced endothelium-dependent vasodilatation in conduction arterioles of elderly rats. However, as with experiments of Spier and colleagues ${ }^{(13,14)}$, the infusion of an NO inhibitor caused a decrease in effect of physical exercise on arterioles. Thus, Spier et al. ${ }^{(13,14)}$ and Trott et al. ${ }^{(15)}$ conclude, physical exercise is able to increase not only eNOS activity but also NO activity. In addition, L-NAME infusion is responsible for changes in endothelium-dependent vasodilation, whereas infusion of L-NAME causes inhibition of adaptations assessed after physical training. As mentioned above, one of the factors leading to decreased NO bioavailability is decoupling of eNOS. In present study, the effect of physical exercise on flow-dependent vasodilatation of resistance arterioles of skeletal muscle in elderly rats was evaluated by Sindler et al. ${ }^{(6)}$. However, influence of NO pathway components 
on this response, also the authors evaluated other factors, such as tetrahydrobiopterin $\mathrm{BH} 4$ and influence of $\mathrm{ROS}$ on vasodilator phenomenon. After 12 weeks of treadmill exercise, the authors observed that elderly rats demonstrated flow-dependent vasodilation as demonstrated by sedentary young rats. Regarding the bioavailability of $\mathrm{BH} 4$, trained elderly rats showed a cofactor increase after 12 weeks of physical exercise; on the other hand, elderly sedentary rats showed decreased protein. In addition, when stimulated NO production (through shear stress), trained elderly rats increased NO production by approximately $14 \%$ and sedentary elderly rats increased by only $5 \%$.

The involvement of bone blood flow that accompanies old age is one of the contributing factors for development of osteoporosis ${ }^{(7)}$. Dominguez et al. ${ }^{(7)}$ submitted elderly rats to 12 weeks of resistance training, and verified whether this stimulus was capable of causing improvements in vascular function of femoral nutrition arteries, and also evaluated whether these alterations contributed to improvements in bone properties. The researchers observed that trained elderly rats demonstrated an increase in endothelium-dependent vasodilation compared to sedentary femoral feeding artery rats. In addition, inhibition of eNOS caused a $75 \%$ decrease in increase of vasodilation caused by physical exercise in arteries of elderly rats. Interestingly, increased endothelium-dependent vasodilation in trained elderly group was accompanied by changes in bone tissue properties, such as increased bone trabecular volume/tissue volume ratio, trabecular number, and trabecular density. Together these results demonstrate that NO is an important factor in regulation of bone density, whereas changes in its bioavailability may lead to bone involvement in old age (eg osteoporosis) ${ }^{(7)}$. The relationship between old age, physical exercise and NO was also studied in the cerebral microcirculation. After being submitted to eight weeks of swimming, elderly rats demonstrated increased eNOS expression in cerebral micro vessels. Accompanied by this, rats presented increased cerebral blood flow and capillary vascularity, as well as decreased oxidative stress compared to control group ${ }^{(8)}$. Decreases in cerebral blood flow may cause long-term impairment of cognition, and ischemic strokes. Thus, maintenance of cerebral vascular homeostasis is essential for quality and survival of elderly population.

Chronic increase in sympathetic activity of central nervous system is one of the factors related to genesis of systemic arterial hypertension, mainly attributed to neurogenic or primary hypertension(16). In this study, patients with hypertension had higher sympathetic activity at rest when compared to normotensive patients, regardless of age and diet (eg, low or high sodium intake). One of the systemic responses to increased sympathetic nerve activity is increased angiotensin II synthesis (ANG II). Juxtaglomerular cells increase renin production after activation of $\beta$-receptors by $N A^{(17)}$. Renin acts on angiotensinogen to form angiotensin I, which will be cleaved by angiotensin-converting enzyme, forming angiotensin II (ANGII) ${ }^{(17)}$. ANGII is related to physiological control of arterial pressure, acting in a central and peripheral way. As for peripheral control, in addition to increased aldosterone secretion, it will contribute to increased sodium retention in proximal contorted tubule, resulting in increased extracellular fluid and blood pressure ${ }^{(17)}$. Ang II also acts on arterial receptors and increases peripheral vasoconstriction. Thus, it is possible to verify that both systems are related, and chronic increase of sympathetic activity will cause increase of circulating levels of ANG II, which in turn can act at the central level (positive feedback) as well as at peripheral level leading to an increase in arterial vasoconstriction, consequently elevating BP. Two experiments evaluated effect of physical exercise on arterial tone, its relation with both systems, and influence of NO modulation.

Donato et al. ${ }^{(18)}$ investigated the effect of 12-week aerobic exercise on $\alpha$-adrenergic receptor mediated vasoconstriction in soleus and gastrocnemius muscle arteries of elderly rats. In addition, the authors verified whether possible changes were mediated by NO. After 12 weeks of training, researchers observed that trained elderly rats had lower NA-induced arteriolar vasoconstriction when compared to sedentary rats. Regarding NO, the researchers maintained the arteriole of the old trained rats in contact with L-NAME, and then again induced vasoconstriction with NA. The absence of protective effect that exercise had caused was verified, since both arterioles (from the sedentary and trained rats) had same percentage of vasoconstriction induced by NA. The authors conclude that physical exercise demonstrates protective role in increase of $\alpha$-adrenergic vasoconstriction that is accompanied by old age. In addition, it was possible to verify that this effect occurs through modulations of NO pathway, however, it is not known exactly how this happens ${ }^{(18)}$. In relation to ANGII, Park et al. ${ }^{(17)}$ verified the relationship between old age, physical exercise, NO and angiotensin II. A priori, it was observed that old age was accompanied by an increase in vasoconstriction response in response to ANG II compared to young rats. However, elderly and trained rats showed lower sensitivity to ANG II, whereas lower arteriolar vasoconstriction was observed after induction by ANG II compared to sedentary elderly rats. However, after inhibition of eNOS and ANG II infusion, it was found that beneficial effects from exercise were abolished ${ }^{(17)}$. Insulin resistance is a condition that precedes the type II diabetic state and shows a high prevalence in the elderly individual. This condition is characterized by the decrease in the relation between insulin and the target organs in which this hormone acts ${ }^{(17)}$. Among the various physiological processes in which insulin collaborates (eg glucose uptake, cardiac chronotropism), endothelium-dependent vasodilation is one of the processes most affected by the insulin resistance state. When insulin binds to the IRS-1 receptor on the cell membrane, a cascade 
of cellular reactions is activated until eNOS phosphorylation ${ }^{(19)}$. In insulin resistance, there is an imbalance between oxidant proteins and antioxidants causing oxidative stress, which leads to the compromise of NO production, decreasing arterial vasodilatation, contributing to the development of systemic arterial hypertension ${ }^{(9)}$. In the study of Li et al. ${ }^{(19)}$ was investigated the potential of physical exercise to positively modulate the mechanisms related to the reduction of endothelium-dependent vasodilation, a product of insulin resistance, in elderly rats. After 10 weeks of swimming in the tank, the elderly rats showed greater sensitivity to insulin, lower blood glucose and insulin values compared to sedentary elderly rats. When insulin-mediated endothelial vasodilation was observed, the researchers observed that elderly rats who had previously exercised demonstrated greater vasodilatation compared to the elderly and sedentary rats. In addition, infusion of L-NAME inhibited the positive changes caused by physical exercise in insulin-mediated vasodilation ${ }^{(19)}$. The researchers further evaluated a possible mechanism by which physical exercise could have acted. The results demonstrated that older trained rats presented lower values of gp91phox and iNOS (markers of oxidative and nitrosative stress) and higher protein expression of eNOS, calveolin-1 and insulin-mediated eNOS phosphorylation when compared to the sedentary elderly group. Thus, researchers conclude that physical exercise may inhibit the insulin resistance status found in the elderly individual ${ }^{(19)}$. In addition, this effect may contribute to the maintenance of endothelium-dependent vasodilatation and reduction of oxidative and nitrosative stress markers, which may act in other pathways, impairing other physiological functions ${ }^{(3)}$.

The reperfusion presents after a coronary ischemic, is extremely damaging the cardiac cells leading to numerous deleterious effects, among them the decrease of the coronary blood flow and the active tension of the cardiac muscles. Le Pagge et al. ${ }^{(20)}$ found that after a state of ischemia and cardiac reperfusion, elderly rats who had previously performed aquatic exercise demonstrated maintenance of cardiac contractile function and coronary blood flow. In addition, the eNOS content was increased in the left ventricle of rats that had previously exercised in comparison to the sedentary ones. These data were confirmed by Tanabe et al..$^{(5)}$. The researchers evaluated that 8 weeks of tank swimming were able to increase the expression of eNOS MRNA and protein in the aorta of trained rats compared to sedentary rats. According to the researchers, it is possible to conclude that increased eNOS content may have exerted protective role in the cardiac myocyte, allowing it to inhibit the exacerbated increase of ROS, collaborated for the increase of angiogenesis and for activation of molecular pathways that maintain the contractile function ${ }^{(5)}$.

Even in relation to angiogenesis, during myocardial infarction, myocardial angiogenesis can be suppressed, causing a decrease in the blood supply to the heart, and consequently cardiovascular diseases ${ }^{(21)}$. lemitsu et al. ${ }^{(21)}$ observed that after 8 weeks of tank swimming, elderly rats showed increased capillary density and capillary / myocyte ratio. In contrast, sedentary elderly rats showed lower values of both factors. In addition, the researchers found that there was an increase in VEGF (vascular endothelial growth factor), a mitogenic factor that has high angiogenic activity in the left ventricle of the elderly rats. In addition, eNOS and its phosphorylated form were also increased in the trained elderly rats. The authors conclude that there is a relationship between the two factors (eNOS and VEGF) and this can be positive feedback, where both are of great importance in angiogenesis. Interestingly, the experiment by lemitsu et al. ${ }^{(21)}$ can corroborate to explain the findings of Le Page et al. ${ }^{(20)}$. Therefore, physical exercise could cause increased phosphorylation of eNOS and subsequently increase NO, in turn increase VEGF and leading to angiogenesis ${ }^{(20,21)}$. The increase of the antioxidant defense can contribute to the reduction of oxidative stress, collaborating with greater $\mathrm{NO}$ availability ${ }^{(3)}$. Eksakulkla et al. ${ }^{(22)}$ verified whether there were differences between antioxidant treatment and physical exercise in endothelial-mediated vasodilation in the cremaster muscle arterioles in elderly rats. In addition, the authors evaluated the impact of both interventions on NO synthesis. After 8 weeks of tank swimming as well as daily genistein nutrition, both groups demonstrated increased vasodilatory ACh response and increased NO synthesis (measured by fluorescence) compared to the same age group. In addition, the authors found a positive association between increased NO and vasodilation size found in arterioles ${ }^{(22)}$. INOS is an isoform of NOS acting as a collaborator of the inflammatory state, thus being related to the inactivation of NO. In this study, we evaluated the impact of aerobic physical exercise on NOS isoforms (i.e., iNOS and $\mathrm{eNOS}^{(23)}$. After 12 weeks of aerobic training, the trained elderly rats demonstrated an $88 \%$ increase in eNOS expression in the gastrocnemius arteriole compared to the sedentary elderly rats. In addition, they found that concomitant increase of eNOS had a $67.8 \%$ decrease in iNOS expression. These results are very important, while demonstrating a possible mechanism responsible for compromising eNOS values ${ }^{(23)}$. A summary of effects of physical exercise in the NO pathway in animal model, can be observed in Table 1.

\section{NO and exercise in elderly humans}

In humans, few studies have studied the impact of physical exercise on NO plasma concentrations, or even the tissue gene expression of the components of their life, and their repercussion on the cardiovascular functionality and homeostasis of the elderly individual. In addition, many experiments are based on cross-sectional methodologies ${ }^{(24-26)}$, and samples that are not composed entirely of elderly subjects ${ }^{(1,2,27)}$. Regarding the cross-sectional model, Taddei et al. ${ }^{(26)}$ investigated the difference in the 
vasodilatory capacity of trained and sedentary healthy and elderly adolescents, in addition to their relationship with NO. The researchers recruited 24 young volunteers and
25 elderly volunteers, who were later stratified into 4 groups from their maximal ventilatory capacity $\left(\mathrm{VO}_{2 \max }\right)$. Participants also underwent Ach-mediated assessment of forearm blood

Table 1. Describes of methodology, investigated component of NO pathway and results of animal model studies evaluated

\begin{tabular}{|c|c|c|c|c|c|c|}
\hline $\begin{array}{c}\text { Year of } \\
\text { Publication }\end{array}$ & First author & Samples & $\begin{array}{l}\text { Physical exercise } \\
\text { methodology }\end{array}$ & Exercise time & $\begin{array}{l}\text { Investigation into the } \\
\text { components of the NO }\end{array}$ & Secondary outcomes \\
\hline 2003 & Tanabe & $\begin{array}{l}\text { Male Wistar rats } \\
\text { ( } 21 \text { months) }\end{array}$ & $\begin{array}{l}\text { Swimming in tank for } \\
90 \text { minutes }\end{array}$ & 5 days / 8 weeks & $\begin{array}{l}\uparrow \text { eNOS (mRNA and } \\
\text { protein) }\end{array}$ & NR \\
\hline 2004 & Spier & $\begin{array}{l}\text { Fischer rats } 344 \\
\text { elderly ( } 22 \text { months) } \\
\text { male }\end{array}$ & $\begin{array}{l}\text { Track run } 15 \mathrm{~m} / \mathrm{min} \text { at } \\
15^{\circ} \text { incline } / 60 \mathrm{~min}\end{array}$ & 5 days / 12 weeks & $\begin{array}{l}\text { inhibition of eNOS, } \uparrow \\
\text { expression of eNOS } \\
\text { protein and mRNA }\end{array}$ & $\begin{array}{l}\text { Restoration of endothelium- } \\
\text { dependent vasodilation }\end{array}$ \\
\hline 2006 & lemitsu & $\begin{array}{l}\text { Male Wistar rats } \\
\text { ( } 21 \text { months) }\end{array}$ & $\begin{array}{l}\text { Swimming in tank for } \\
90 \text { minutes }\end{array}$ & 5 days / 8 weeks & $\begin{array}{l}\text { 个 expression of } \\
\text { eNOS and eNOS } \\
\text { phosphorylated }\end{array}$ & $\begin{array}{l}\text { Increased capillary density } \\
\text { and capillary / myocyte ratio }\end{array}$ \\
\hline 2007 & Spier & $\begin{array}{l}\text { Fischer rats } 344 \\
\text { elderly ( } 22 \text { months) } \\
\text { male }\end{array}$ & $\begin{array}{l}\text { Track run } 15 \mathrm{~m} / \mathrm{min} \text { at } \\
15^{\circ} \text { incline } / 60 \mathrm{~min}\end{array}$ & 5 days / 12 weeks & Inhibition of eNOS & $\begin{array}{l}\text { Restoration of flow-induced } \\
\text { vasodilatation }\end{array}$ \\
\hline 2007 & Donato & $\begin{array}{l}\text { Fischer rats } 344 \\
\text { elderly ( } 26 \text { months) } \\
\text { male }\end{array}$ & $\begin{array}{l}\text { Track run } 15 \mathrm{~m} / \mathrm{min} \text { at } \\
15^{\circ} \text { incline } / 60 \mathrm{~min}\end{array}$ & 5 days / 12 weeks & Inhibition of eNOS & $\begin{array}{l}\text { Inhibition of vasoconstrictor } \\
\text { response induced by NA in } \\
\text { arterioles }\end{array}$ \\
\hline 2007 & Bearden & $\begin{array}{l}\text { rats C57BL6 elderly } \\
\text { (19-21 months) } \\
\text { males }\end{array}$ & $\begin{array}{l}\text { Volunteer running on a } \\
\text { treadmill }\end{array}$ & 8 weeks & $\uparrow$ expression of eNOS & $\begin{array}{l}\text { Absence of changes in } \\
\text { conduction arteries }\end{array}$ \\
\hline 2009 & Song & $\begin{array}{l}\text { Fischer rats } 344 \\
\text { elderly ( } 24 \text { months) } \\
\text { male }\end{array}$ & $\begin{array}{l}\text { Track run } 15 \mathrm{~m} / \mathrm{min} \text { at } \\
15^{\circ} \text { incline } / 60 \mathrm{~min}\end{array}$ & 5 days / 12 weeks & $\begin{array}{l}\uparrow \text { protein expression } \\
\text { of eNOS }\end{array}$ & Decrease iNOS \\
\hline 2009 & Sindler & $\begin{array}{l}\text { Fischer rats } 344 \\
\text { elderly ( } 22 \text { months) } \\
\text { male }\end{array}$ & $\begin{array}{l}\text { Track run } 15 \mathrm{~m} / \mathrm{min} \text { at } \\
15^{\circ} \text { incline } / 60 \mathrm{~min}\end{array}$ & 5 days / 12 weeks & $\begin{array}{l}\text { Inhibition of eNOS, } \\
\uparrow N O\end{array}$ & $\begin{array}{l}\text { Restoration of vasodilatation } \\
\text { Increase of } \mathrm{BH} 4\end{array}$ \\
\hline 2009 & $\mathrm{Li}$ & $\begin{array}{l}\text { Male Sprague-Dawley } \\
\text { rats ( } 24 \text { months) }\end{array}$ & $\begin{array}{l}\text { Swimming in tank for } \\
60 \text { minutes }\end{array}$ & 5 days / 10 weeks & $\begin{array}{l}\text { Inhibition of eNOS, } \uparrow \\
\text { Caveolin-1, } \uparrow \text { eNOS, } \\
\text { phosphorylated eNOS }\end{array}$ & $\begin{array}{l}\text { Inhibition of } \\
\text { hypertensive response } \\
\text { to hyperinsulinemia, } \\
\text { restoration of insulin } \\
\text { dependent vasodilatation } \\
\text { and improvement of cardiac } \\
\text { function }\end{array}$ \\
\hline 2009 & Le Page & $\begin{array}{l}\text { Male Wistar rats } \\
\text { ( } 24 \text { months) }\end{array}$ & $\begin{array}{l}\text { Track run } 15 \mathrm{~m} / \mathrm{min} \text { at } \\
15^{\circ} \text { incline } / 60 \mathrm{~min}\end{array}$ & 5 days / 12 weeks & $\uparrow$ expression of eNOS & $\begin{array}{l}\text { Preservation of contractile } \\
\text { function and coronary flow } \\
\text { after I.R. }\end{array}$ \\
\hline 2009 & Trott & $\begin{array}{l}\text { Fischer rats } 344 \\
\text { elderly ( } 24 \text { months) } \\
\text { male }\end{array}$ & $\begin{array}{l}\text { Track run } 15 \mathrm{~m} / \mathrm{min} \text { at } \\
15^{\circ} \text { incline } / 60 \mathrm{~min}\end{array}$ & 5 days / 12 weeks & $\begin{array}{l}\text { inhibition of eNOS, } \\
\text { expression of eNOS }\end{array}$ & $\begin{array}{l}\text { Increased endothelium- } \\
\text { dependent vasodilation }\end{array}$ \\
\hline 2009 & Eksakilkla & $\begin{array}{l}\text { Male Wistar rats } \\
\text { ( } 22 \text { months) }\end{array}$ & $\begin{array}{l}\text { Swimming in tank for } \\
40 \text { minutes }\end{array}$ & 5 days / 8 weeks & $\uparrow$ Synthesis of NO & $\begin{array}{l}\text { Increased endothelium- } \\
\text { dependent vasodilation }\end{array}$ \\
\hline 2009 & Durrant & $\begin{array}{l}\text { Mice B6D2F1 } \\
\text { (32 months) male }\end{array}$ & $\begin{array}{l}\text { Volunteer running on a } \\
\text { treadmill }\end{array}$ & 12 weeks & $\begin{array}{l}\text { Inhibition of eNOS, } \uparrow \\
\text { eNOS, } \uparrow \text { eNOS activity }\end{array}$ & $\begin{array}{l}\text { Increased endothelium- } \\
\text { dependent vasodilation }\end{array}$ \\
\hline 2010 & Dominguez & $\begin{array}{l}\text { Fischer rats } 344 \\
\text { elderly ( } 26 \text { months) } \\
\text { male }\end{array}$ & $\begin{array}{l}\text { Track run } 15 \mathrm{~m} / \mathrm{min} \text { at } \\
15^{\circ} \text { incline } / 60 \mathrm{~min}\end{array}$ & 5 days / 12 weeks & Inhibition of eNOS & $\begin{array}{l}\text { Increased endothelium- } \\
\text { dependent vasodilation }\end{array}$ \\
\hline 2012 & Park & $\begin{array}{l}\text { Fischer rats } 344 \\
\text { elderly ( } 22 \text { months) } \\
\text { male }\end{array}$ & $\begin{array}{l}\text { Track run } 15 \mathrm{~m} / \mathrm{min} \text { at } \\
15^{\circ} \text { incline } / 60 \mathrm{~min}\end{array}$ & 5 days / 12 weeks & Inhibition of eNOS & $\begin{array}{l}\text { Inhibition of ANG II induced } \\
\text { vasoconstrictor response in } \\
\text { arterioles }\end{array}$ \\
\hline 2014 & Viboolvorakul & $\begin{array}{l}\text { Male Wistar rats } \\
\text { ( } 21 \text { months) }\end{array}$ & $\begin{array}{l}\text { Swimming in tank for } \\
60 \text { minutes }\end{array}$ & 5 days / 8 weeks & $\uparrow$ expression of eNOS & $\begin{array}{l}\text { Increased cerebral blood } \\
\text { flow, increased capillary } \\
\text { density, decreased ROS }\end{array}$ \\
\hline
\end{tabular}

Note: $\mathrm{NO}=$ nitric oxide, $\mathrm{ROS}=$ reactive oxygen species, eNOS = endothelial nitric oxide synthase, iNOS = nitric oxide synthase induced, NA = noradrenaline, ANGII = angiotensin II, I.R. = ischemia / reperfusion 
flow (FBF) (a form of measurement of endothelium-dependent vasodilation), as well as inhibition of NO synthesis by L-NMMA infusion, and stimulation of antioxidant defense by infusion of ascorbic acid (ie, vitamin $\mathrm{C}$ ). The results showed that the elderly had FBF decrease compared to the young. However, when evaluated for differences within the elderly group, the trained ones showed higher FBF than the sedentary group. In all cases, the L-NMMA infusion caused a decrease in FBF found in the trained elderly group, and did not affect the sedentary group. On the other hand, vitamin $C$ infusion increased FBF in the sedentary elderly ${ }^{(26)}$. The researchers conclude that physical exercise may delay the decline in endothelial vasodilator capacity found during old age, while trained elderly patients had higher ACh-induced FBF compared to sedentary patients. Regarding the possible mechanisms, the physical exercise seems to collaborate with the maintenance of the endothelial capacity in synthesizing the NO, most probably, by preventing the exacerbated increase of ROS production. That way, acting as an antioxidant.

Another study using a cross-sectional study evaluated the difference in the vasodilatory response to ACh in two groups, one composed of elderly people who were largely sedentary and the other by elderly people who were largely physically active $^{(25)}$. The results showed that the elderly who had remained active during the life showed a great vasodilator response in comparison to the sedentary ones. In addition, eNOS expression was $32 \%$ higher in the thigh muscle of the trained elderly compared to the sedentary elderly. The researchers also evaluated the possible mechanism by which physical exercise protected the vascular endothelium, contributing to higher NO production, causing a greater response to ACh. Both groups were submitted to infusion of an antioxidant substance, however only the sedentary group demonstrated an increase in plasma NO concentrations. These results demonstrated that long-term physical exercise may cause a decrease or even delay the oxidative effects caused by old age, which, in turn, lead to NO deterioration and impairment of vascular homeostasis ${ }^{(25)}$. Black et al. ${ }^{(24)}$ performed a very elegant work and evaluated in two ways the relationship between physical exercise, vasodilator capacity of microcirculation induced by physiological and pharmacological stress, and old age. In the first form, a cross section was used, where the researchers evaluated 3 different groups, one composed by moderately active youngsters, the other by sedentary adults and the last by active adults (evaluated by $\mathrm{VO}_{2 \max }$ ). The results showed that the sedentary elderly had a lower contribution of NO in the vasodilation of the heat-induced microcirculation compared to the young and active elderly. When the response to pharmacological stress (ACh) was evaluated, the active elderly had a higher cutaneous vascular conductance (CVC) than the sedentary elderly. However, this difference was inhibited by infusion of L-NAME ${ }^{(24)}$. In the second part of the study, the sedentary elderly who presented lower NO response to physiological and pharmacological stress, as well as lower vasodilatory response to $\mathrm{ACh}$, were divided into two groups. One group was submitted to 24 weeks of regular exercise, performed at $60 \%$ of the reserve heart rate, the other, in turn, was maintained without physical or nutritional intervention. After the intervention, the sedentary elderly showed increased NO contribution in physiologically induced dilation and ACh, as well as an increase in ACh-mediated vasodilation. In addition, after the intervention, the sedentary elderly presented equal values to the trained elderly and moderately active youngsters. In conclusion, it is possible to observe that physical exercise collaborates in the synthesis and functionality of NO, thus collaborating with vascular homeostasis. In addition, physical exercise may reverse the deleterious effect on vasodilatation found in vessels during the elderly life ${ }^{(24)}$.

Other experiments evaluated the effect of chronic physical exercise intervention on NO concentrations in the elderly. Maeda et al. ${ }^{(28)}$ submitted 15 apparently healthy elderly women to three months of intervention per physical exercise. After being randomized into two groups (i.e. exercise and sedentary), the exercise group underwent a moderate intensity aerobic training protocol ( $80 \%$ ventilatory threshold) lasting 30 minutes, five times a week. After three months of intervention, the researchers observed a decrease in systolic blood pressure, diastolic blood pressure and plasma triglyceride concentrations in the exercise group. In addition, the exercise group demonstrated higher plasma concentrations of NO and cGMP compared to the baseline and the sedentary group. Interestingly, the percentage of changes in NO values showed a negative relationship with changes in SBP. In another study of the same group, Maeda et al. ${ }^{(29)}$ submitted 11 sedentary elderly men to 12 weeks of physical exercise in isokinetic dynamometer. Using an uncommon exercise protocol consisting of only one exercise, which was performed from three sets with 10 repetitions of knee flexion and extension. After 12 weeks of intervention, the researchers observed increased NO compared to baseline. However, there were no changes in cardiovascular function. Brinkley et al. ${ }^{(27)}$ evaluated the impact of 24 weeks of aerobic exercise on plasma NO concentrations and blood flow in the forearm in response to occlusion. After the intervention time the authors did not identify changes in both factors studied. However, despite the lack of alterations after the intervention, the experiment has some methodological limitations that could compromise the study, such as the average age of the volunteers, which varied between 50 and 75 years, and the body composition, which, before the index of body mass, was classified as overweight.

Recently, Fujie et al. ${ }^{\left({ }^{30}\right)}$ verified the effect of eight weeks of aerobic exercise on plasma NO concentrations and arterial stiffness of sedentary elderly subjects. The trained elderly showed a decrease in carotid artery stiffness after the intervention, accompanied by an increase in NO concentrations in relation to the baseline and control groups. 
Table 2. Describes of methodology, investigated component of NO pathway and results of human studies

\begin{tabular}{|c|c|c|c|c|c|c|}
\hline $\begin{array}{l}\text { Year of } \\
\text { Publication }\end{array}$ & $\begin{array}{c}\text { First } \\
\text { author }\end{array}$ & Samples & Physical exercise methodology & Exercise time & $\begin{array}{l}\text { Investigation into } \\
\text { the components of } \\
\text { the NO }\end{array}$ & $\begin{array}{l}\text { Secondary } \\
\text { outcomes }\end{array}$ \\
\hline 2000 & Taddei & $\begin{array}{l}\text { Sedentary and trained } \\
\text { elders }\end{array}$ & NA & NA & inhibition of eNOS & $>\mathrm{FBF}$ \\
\hline 2004 & Maeda & Healthy elders & $\begin{array}{l}30 \mathrm{~min} \text { on cycle ergometer at } \\
80 \% \mathrm{LV}\end{array}$ & 5 days / 3 months & ‘个NO 个cGMP & $\begin{array}{l}\downarrow \text { PAS, PAD and } \\
\text { triacylglycerol }\end{array}$ \\
\hline 2006 & Maeda & Healthy elders & $\begin{array}{l}3 \text { sets / } 10 \text { repetitions / flexion } \\
\text { and extension of the knees in } \\
\text { isokinetic / } 60 \% 1 \mathrm{RM}\end{array}$ & 2 days / 12 weeks & ‘个NO & $\begin{array}{l}\downarrow \text { serum insulin, } \\
\uparrow \text { potency of the } \\
\text { lower limbs }\end{array}$ \\
\hline 2008 & Black & Sedentary and active elders & NA & NA & inhibition of eNOS & $'>\% \mathrm{CVC}$ (ACh) \\
\hline 2008 & Black & Sedentary and active elders & $\begin{array}{l}30 \mathrm{~min} \text { of treadmill and bicycle } \\
\text { in } 60 \% \mathrm{FCr}\end{array}$ & 5 days / 24 weeks & inhibition of eNOS & $\uparrow \% C V C(A C h)$ \\
\hline 2009 & Brinkley & $\begin{array}{l}\text { sedentary and overweight } \\
\text { adults and elders }\end{array}$ & $\begin{array}{l}40 \text { min in treadmill at } 70 \% \text { VO2 } \\
\max \end{array}$ & 4 days / 24 weeks & $‘=\mathrm{NO}$ & $'=\mathrm{FBF}$ \\
\hline 2010 & Zago & Sedentary elders & $\begin{array}{l}40 \text { min in treadmill at } 70 \% \text { VO2 } \\
\max \end{array}$ & 3 days / 6 months & ‘个NO & $\downarrow$ PAS e PAD \\
\hline 2010 & Zago & Sedentary elders & $\begin{array}{l}40 \text { min in treadmill at } 70 \% \text { VO2 } \\
\max \end{array}$ & 3 days / 6 months & ‘个NO & $\downarrow$ PAS e PAD \\
\hline 2012 & Nyberg & $\begin{array}{l}\text { Sedentary and trained } \\
\text { elders }\end{array}$ & NA & NA & >eNOS & $>\mathrm{FMBF}$ \\
\hline 2014 & Fujie & Sedentary elders & $\begin{array}{l}55 \text { min leg ergometer at } 70 \% \\
\text { VO2 max }\end{array}$ & 3 days / 8 weeks & '个NO & $\begin{array}{l}\downarrow \text { Carotid arterial } \\
\text { rigidity }\end{array}$ \\
\hline
\end{tabular}

Note: $\mathrm{NO}=$ nitric oxide, $\mathrm{ROS}=$ reactive oxygen species, eNOS = endothelial nitric oxide synthase, iNOS = induced nitric oxide synthase, NA = noradrenaline, $\mathrm{ANGII}=$ angiotensin II, I.R. = ischemia / reperfusion

In addition, the researchers also observed an increase in the concentration of Apelin, a protein that contributes to endothelial vasodilation, and is stimulated by NO. Still in relation to Apelin, the statistical analysis showed a negative correlation between changes in Apelin concentrations and carotid artery stiffness, after eight weeks of intervention. However, changes in plasma concentrations of Apelin showed a positive correlation with NO changes ${ }^{(30)}$. Two studies of the same group studied the influence of the polymorphism of the gene encoding the NO synthase (eNOS) in NO concentrations, as well as whether genotypic differences could compromise the response to physical exercise ${ }^{(1,2)}$. The first experiment distributed 118 pre-hypertensive sedentary elderly people in four groups according to their genotype, being a group that had no polymorphism, one with T allele (G-894T), one with $C$ allele (T-786C), and one that had the two $C+T$ (1). A priori, the group that possessed the two alleles ( $\mathrm{C}$ and $\mathrm{T}$ ) had the lowest concentrations of NO compared to the other three groups. After six months of intervention, the same group that presented lower concentrations of NO showed an increase in NO concentrations, followed by a decrease in blood pressure values. However, the other three groups did not demonstrate significant changes in blood pressure values as well as NO concentrations. In the second group work ${ }^{(2)}$, the authors separated the volunteers by owning or not the $C$ allele (T-786C). Again, the T-786C group demonstrated lower NO concentrations compared to the control. After being submitted to the same training protocol of the first study, only the group that had the $\mathrm{C}$ allele demonstrated an increase in NO concentrations. A summary of effects of physical exercise in the NO pathway in human model, can be observed in Table 2 .

\section{CONCLUSIONS}

In present study, it was possible to verify that scientific evidences demonstrate effectiveness of the physical exercise in inhibiting decrease of bioavailability in NO which accompanies senescence, greater magnitude and senility. All studies demonstrated physical exercise could cause an increase in the pathway leading to NO synthesis, as well as its plasma concentrations. In elderly, cross-sectional studies show evidence that physical exercise can contribute to maintenance of NO concentrations; thus preserving functional capacity of the organic system. A few studies used interventions to verify relationship of NO, exercise and elderly. Although these studies confirm data already demonstrated in animals and verify that effect of the intervention can also cause increase of NO in humans; it is important to mention that none of experiments had NO as a primary result of the study. Thus, new studies in elderly should be performed studying new forms of exercise, elderly with and without aggregate pathologies and using a random distribution from NO concentrations. However, according to data presented it is possible to infer that physical exercise can contribute to maintenance and increase of NO concentrations in elderly individuals, allowing the physiological system to maintain their functions related to activity of this free radical. 


\section{AUTHORS' CONTRIBUTIONS}

$\mathrm{HJCJ}$ conceived of the presented idea. $\mathrm{HJCJ}$ and SSA developed the theory and performed the computations: RS, RCRP, HOC, SA and RYA verified the analytical methods. SSA and $\mathrm{HJCJ}$ encouraged them to investigate nitric oxide and supervised the findings of this work. All authors discussed the results and contributed to the final manuscript. SSA, RYA, Coelho Júnior HJ, HOC, and SA analyzed the data and they wrote the paper with input from all authors. All authors contributed to the design and implementation of the research, to the analysis of the results and to the writing of the manuscript; finally, all authors read and approved the final manuscript.

\section{CONFLICTS OF INTEREST}

The author(s) declare that they have no competing interests.

\section{AUTHORS DETAILS}

${ }^{1}$ Escola de Educação Física, Universidade Católica de Brasília, Brasília (DF), Brasil. ${ }^{3}$ Escola de Artes, Ciências e Humandiades, Universidade de São Paulo, São Paulo (SP), Brasil. ${ }^{4}$ Escola de Educação Física, Centro Universitário Estácio de Sá, Brasília (DF), Brasil.

\section{REFERENCES}

1. Zago AS, Kokubun E, Fenty-Stewart N, Park JY, Attipoe S, Hagberg J, et al. [Effect of physical activity and t-786C polymorphism in blood pressure and blood flow in the elderly]. Arq Bras Cardiol. 2010;95(4):510-6.

2. Zago AS, Park JY, Fenty-Stewart N, Kokubun E, Brown MD. Effects of aerobic exercise on the blood pressure, oxidative stress and eNOS gene polymorphism in pre-hypertensive older people. Eur J Appl Physiol. 2010;110(4):825-32.

3. El Assar M, Angulo J, Rodríguez-Mañas L. Oxidative stress and vascular inflammation in aging. Free Radical Biology and Medicine. 2013;65:380401.

4. Asano RY, Sales MM, Browne RAV, Moraes JFVN, Júnior HJC, Moraes $\mathrm{MR}$, et al. Acute effects of physical exercise in type 2 diabetes: a review. World journal of diabetes. 2014;5(5):659.

5. Tanabe T, Maeda S, Miyauchi T, lemitsu M, Takanashi M, IrukayamaTomobe $Y$, et al. Exercise training improves ageing-induced decrease in eNOS expression of the aorta. Acta Physiol Scand. 2003;178(1):3-10.

6. Sindler AL, Delp MD, Reyes R, Wu G, Muller-Delp JM. Effects of ageing and exercise training on eNOS uncoupling in skeletal muscle resistance arterioles. J Physiol. 2009;587(Pt 15):3885-97.

7. Dominguez JM, 2nd, Prisby RD, Muller-Delp JM, Allen MR, Delp MD. Increased nitric oxide-mediated vasodilation of bone resistance arteries is associated with increased trabecular bone volume after endurance training in rats. Bone. 2010;46(3):813-9.

8. Viboolvorakul S, Patumraj S. Exercise training could improve agerelated changes in cerebral blood flow and capillary vascularity through the upregulation of VEGF and eNOS. BioMed research international. $2014 ; 2014$.

9. Forstermann U. Nitric oxide and oxidative stress in vascular disease. Pflugers Arch. 2010;459(6):923-39.

10. American College of Sports M, Chodzko-Zajko WJ, Proctor DN, Fiatarone Singh MA, Minson CT, Nigg CR, et al. American College of Sports Medicine position stand. Exercise and physical activity for older adults. Med Sci Sports Exerc. 2009;41(7):1510-30.

11. Bearden SE, Linn E, Ashley BS, Looft-Wilson RC. Age-related changes in conducted vasodilation: effects of exercise training and role in functional hyperemia. Am J Physiol Regul Integr Comp Physiol. 2007;293(4):R171721.

12. Durrant JR, Seals DR, Connell ML, Russell MJ, Lawson BR, Folian BJ, et al. Voluntary wheel running restores endothelial function in conduit arteries of old mice: direct evidence for reduced oxidative stress, increased superoxide dismutase activity and down-regulation of NADPH oxidase. The Journal of Physiology. 2009;587(13):3271-85.
13. Spier SA, Delp MD, Meininger CJ, Donato AJ, Ramsey MW, Muller-Delp JM. Effects of ageing and exercise training on endothelium-dependent vasodilatation and structure of rat skeletal muscle arterioles. J Physiol. 2004;556(Pt 3):947-58.

14. Spier SA, Delp MD, Stallone JN, Dominguez JM, 2nd, Muller-Delp JM. Exercise training enhances flow-induced vasodilation in skeletal muscle resistance arteries of aged rats: role of PGI2 and nitric oxide. Am J Physiol Heart Circ Physiol. 2007;292(6):H3119-27.

15. Trott DW, Gunduz F, Laughlin $\mathrm{MH}$, Woodman CR. Exercise training reverses age-related decrements in endothelium-dependent dilation in skeletal muscle feed arteries. J Appl Physiol (1985). 2009;106(6):1925-34.

16. Consolim-Colombo F, Irigoyen M, Krieger E. Papel dos principais componentes na gênese da hipertensão arterial: sistema nervoso simpático. Brandão AA, Amodeo C, Nobre F Hipertensão 2a ed Rio de Janeiro: Elsevier. 2012:53-9.

17. Park Y, Prisby RD, Behnke BJ, Dominguez JM, 2nd, Lesniewski LA, Donato AJ, et al. Effects of aging, TNF-alpha, and exercise training on angiotensin II-induced vasoconstriction of rat skeletal muscle arterioles. J Appl Physiol (1985). 2012;113(7):1091-100.

18. Donato AJ, Eskurza I, Silver AE, Levy AS, Pierce GL, Gates PE, et al. Direct evidence of endothelial oxidative stress with aging in humans: relation to impaired endothelium-dependent dilation and upregulation of nuclear factor-kappaB. Circ Res. 2007;100(11):1659-66.

19. Li Q-X, Xiong Z-Y, Hu B-P, Tian Z-J, Zhang H-F, Gou W-Y, et al. Agingassociated insulin resistance predisposes to hypertension and its reversal by exercise: the role of vascular vasorelaxation to insulin. Basic research in cardiology. 2009;104(3):269.

20. Le Page C, Noirez P, Courty J, Riou B, Swynghedauw B, Besse S. Exercise training improves functional post-ischemic recovery in senescent heart. Exp Gerontol. 2009;44(3):177-82.

21. lemitsu M, Maeda S, Jesmin S, Otsuki T, Miyauchi T. Exercise training improves aging-induced downregulation of VEGF angiogenic signaling cascade in hearts. Am J Physiol Heart Circ Physiol. 2006;291(3):H1290-8.

22. Eksakulkla S, Suksom D, Siriviriyakul P, Patumraj S. Increased NO bioavailability in aging male rats by genistein and exercise training: using 4 , 5-diaminofluorescein diacetate. Reproductive Biology and Endocrinology. 2009;7(1):93.

23. Song W, Kwak HB, Kim JH, Lawler JM. Exercise training modulates the nitric oxide synthase profile in skeletal muscle from old rats. J Gerontol A Biol Sci Med Sci. 2009;64(5):540-9.

24. Black MA, Green DJ, Cable NT. Exercise prevents age-related decline in nitric-oxide-mediated vasodilator function in cutaneous microvessels. The Journal of physiology. 2008;586(14):3511-24

25. Nyberg M, Blackwell JR, Damsgaard R, Jones AM, Hellsten Y, Mortensen SP. Lifelong physical activity prevents an age-related reduction in arterial and skeletal muscle nitric oxide bioavailability in humans. J Physiol. 2012;590(21):5361-70.

26. Taddei S, Galetta F, Virdis A, Ghiadoni L, Salvetti G, Franzoni F, et al. Physical activity prevents age-related impairment in nitric oxide availability in elderly athletes. Circulation. 2000;101(25):2896-901.

27. Brinkley TE, Fenty-Stewart NM, Park JY, Brown MD, Hagberg JM. Plasma nitrate/nitrite levels are unchanged after long-term aerobic exercise training in older adults. Nitric Oxide. 2009;21(3-4):234-8.

28. Maeda S, Tanabe T, Otsuki T, Sugawara J, lemitsu M, Miyauchi T, et al. Moderate regular exercise increases basal production of nitric oxide in elderly women. Hypertens Res. 2004;27(12):947-53.

29. Maeda S, Otsuki T, lemitsu M, Kamioka M, Sugawara J, Kuno S, et al. Effects of leg resistance training on arterial function in older men. $\mathrm{Br} \mathrm{J}$ Sports Med. 2006;40(10):867-9.

30. Fujie S, Sato K, Miyamoto-Mikami E, Hasegawa N, Fujita S, Sanada K, et al. Reduction of arterial stiffness by exercise training is associated with increasing plasma apelin level in middle-aged and older adults. PLoS One. 2014;9(4):e93545. 